Article

\title{
Simulation Methodology Based on Wind and Thermal Performance for Early Building Optimization Design in Taiwan
}

\author{
Chuan-Hsuan Lin (D, Min-Yang Chen and Yaw-Shyan Tsay *(D) \\ Department of Architecture, National Cheng Kung University, 1 University Road, Tainan City 701, Taiwan; \\ visdr207@gmail.com (C.-H.L.); awdfgh21354@gmail.com (M.-Y.C.) \\ * Correspondence: tsayys@mail.ncku.edu.tw
}

Citation: Lin, C.-H.; Chen, M.-Y.; Tsay, Y.-S. Simulation Methodology Based on Wind and Thermal Performance for Early Building Optimization Design in Taiwan. Sustainability 2021, 13, 10033. https:/ / doi.org/10.3390/su131810033

Academic Editor: Hamidreza Najafi

Received: 16 August 2021

Accepted: 3 September 2021

Published: 7 September 2021

Publisher's Note: MDPI stays neutral with regard to jurisdictional claims in published maps and institutional affiliations.

Copyright: (c) 2021 by the authors. Licensee MDPI, Basel, Switzerland. This article is an open access article distributed under the terms and conditions of the Creative Commons Attribution (CC BY) license (https:// creativecommons.org/licenses/by/ $4.0 /)$.

\begin{abstract}
In a subtropical climate like that of Taiwan, the high temperature and humid environmental conditions often result in discomfort and health effects for building occupants. With regard to building geometry, the wind environment and thermal comfort assessment, which can enhance energy efficiency and the comfort and health of occupants, both ought to be considered as soon as possible in the design process. In view of the limited comprehensive design evaluation methods and design workflows regarding wind and thermal performance currently available, this research aims to develop an early decision support workflow that includes suggested performance evaluation methods and design optimization processes. The results of our case study show that the building had clear performance results using the proposed evaluation methods, making it easier for architects to understand and compare alternatives. Appropriate analysis and visualization of the results also effectively assisted architects in determining design solutions and making relevant decisions. The methods and results in this article can facilitate performance-based buildings for healthy and energy-efficient built environments.
\end{abstract}

Keywords: building performance simulation; optimization algorithm; green building design; wind environment; thermal comfort; decision support workflow

\section{Introduction}

As energy issues become increasingly important to building design and people's demand for a comfortable quality of life increases, the discussions surrounding building environmental performance assessment have increased considerably in recent years. For passive architectural design based on different climates, these performance assessments are especially important in the early stage of building design, since many critical design decisions (e.g., orientation, layout, massing, fenestration, and shading [1]) are usually made at this stage and have the most significant impact on overall building performance (e.g., building life-cycle cost) [2,3].

Most of the building consumption is related to the use of active systems to maintain the occupants' comfort. The passive design can maximally utilize the local conditions (e.g., sunlight/wind/surroundings) to improve occupants' comfort and decrease energy consumption. For example, in the subtropical climate of Taiwan, where summers are hot and humid, thermal comfort both indoor and outdoor has always been a crucial issue. The environmental conditions of high temperatures and humidity make people feel uncomfortable and can even affect physical and mental health [4,5], and effective ventilation has often been seen as a desirable solution [6-8]. Natural ventilation supplies and removes air to and from indoor and outdoor spaces through natural wind forces and buoyancy, which has shown great potential for reducing the energy required for cooling and ventilating a building and improving thermal comfort $[6,7,9,10]$. Ventilation as an essential determinant of indoor air quality and thermal comfort has been highlighted in previous studies [11,12], and is considered to be one of the main passive design strategies in tropical climates to avoid air-conditioning [13-15]. 
To realize the potential benefits of natural ventilation, the characteristics of local climate must be thoroughly considered, and the wind field and thermal comfort performance of each design alternative must be evaluated in the design process. However, the previous studies mostly focus on comfort parameters at a certain time and position in space, and there are few overall evaluation methods that span time and space that can be used in the design process $[13,16]$.

The assessment of wind environment performance includes the building's natural ventilation and the pedestrian level wind field around the building. In terms of a building's natural ventilation, evaluation indicators consist of minimum ventilation rate [17], ventilation efficiency [18], and age of air [19], among others. The information required for these evaluation indicators is usually unknown in the early design stage, making its adoption difficult for early design assessment [20]. The pedestrian level wind field also has relevant indicators [21-24], but they are mainly used for picking strong wind situations and are unsuitable for checking normal wind conditions [25]. Evaluating pedestrian wind field requires two pieces of data: defined wind speed level and the allowable occurrence frequency of each level. Therefore, it requires long-term record data to conduct evaluation, rendering this factor difficult to implement in early design.

Many thermal comfort indices are available [16,26,27], such as physiological equivalent temperature (PET) [28], universal thermal climate index (UTCI) [29], and standard effective temperature (SET) [30]. These indices usually require such meteorological data as temperature, humidity, and wind speed for calculation. For example, PET was developed from the Munich Energy-balance Model for Individuals (MEMI) and is defined as equivalent to the air temperature required to reproduce the core and skin temperatures in a standardized indoor setting and for a standardized person, respectively [28,31]. PET is controlled by meteorological parameters (air temperature, air humidity, wind velocity, mean radiant temperature) and thermo-physiological parameters (heat resistance of clothing, activity of humans). UTCI is an equivalent temperature $\left({ }^{\circ} \mathrm{C}\right)$ that is a measure of the human physiological response to the thermal environment. UTCI is defined as the capability of an organism to retain its body temperature within a particular limit even if the surrounding temperature is completely different. The four parameters required to calculate UTCI are air temperature, relative humidity, wind speed at $10 \mathrm{~m}$ above ground level, and mean radiant temperature (MRT) [32]. These indices are calculated separately according to the data of each position.

Overall, while these wind and thermal comfort-related indicators can be obtained at a specific time period and at a specific location, they cannot give an overall evaluation that represents the performance of design alternatives. However, the fact is that the effects of buildings on the surrounding, internal, and external environments vary with seasonal conditions and locations. In particular, the life cycle of a building after construction may exceed 50 years [33], so the impacts of a building on the future environment can be quite far-reaching. Therefore, from the architectural design perspective, the influences on the future environment in time and space should be considered more comprehensively. With the limitations of the existing evaluation methods, how to evaluate the overall architectural design performance of dynamic time and space to assist architects' decision-making in the early design stage is an important issue.

With the development of various emerging tools (e.g., parametric design, evolutionary algorithms), a smooth and effective process of integrated design and environmental evaluation is taking shape. One promising method is to use automated mathematical building performance optimization (BPO) to introduce various assessments into the early design process. Performance optimization is a process that aims at selection of the optimal solutions through mathematical optimization algorithms (e.g., Genetic Algorithm, Simulated Annealing, Particle Swarm Optimization) from a set of available alternatives for a given design or control problem, according to custom performance indicators [34]. BPO integrated optimization algorithm with environmental evaluation methods (e.g., building performance simulation) to explore various design options (e.g., different combinations 
of orientation, building dimension, WWR and shading device) and obtain the optimal or near optimal solutions (e.g., lowest life-cycle cost, lowest cooling or heating loads, and highest thermal comfort). For better building performance, designers modified their design variables and then ran many simulations to the effect of the design changes on the results. The method would be inefficient procedure in time and labor especially when building design is more complex and more design parameters need to be studied. The BPO technologies can overcome the difficulties and enhance the application of simulation tools [35]. Compared with the traditional "full-field exploration method" that performs a one-by-one assessment, BPO shortens the evaluation time using optimization algorithms and can thus realize the best design alternative more quickly and effectively [36,37].

Recently, the design method using BPO has been rapidly developed. A large number of studies have shown that BPO can significantly improve building performance [38]. For example, Kämpf and Robinson used a hybrid CMA-ES/HDE algorithm and RADIANCE for evaluation to search for the best architectural and urban geometrical solutions using solar radiation [39]. Delgarm used artificial bee colony algorithm and optimized building orientation, window size, materials, and HVAC setting temperature, resulting in an energy consumption reduction of $2.9-11.3 \%$ and improving thermal comfort by $49.1-56.8 \%$ [ 40$]$. Zhang used genetic algorithm and optimized building orientation, depth, window-to-wall ratio (WWR), and shading type, thereby reducing building energy consumption by $24-28 \%$ and thermal discomfort by 9-23\% [41]. Carlucci used NSGA-II algorithm to optimize window materials and light and dark control strategies to obtain the best combination according to thermal discomfort and lighting discomfort and optimization efficiency [42] Talaei used SPEA-2 to optimize the building-integrated microalgae bioreactor design on the facade according to maximum useful daylight intensity (UDI) and minimum energy use intensity (EUI) [43].

As mentioned, early design decisions in the building design process have the greatest impact on the life cycle costs of a building's environmental performance. Despite the great potential for high-performance building design, BPO largely remains a research tool and is challenging to use in early design practice $[38,44]$. The main obstacles include a lack of appropriate tools, a lack of such resources such as time and expertise, and requirements for clearly defined issues (e.g., constraints, objective function, and finite list of design options) [35].

The aim of this manuscript was to develop an early-stage BPO workflow based on integrating design thinking and environmental assessment in the architectural design process. Due to its importance to environmental impact and energy consumption, we focused environmental assessment in this study on the terms of wind field and thermal comfort. Because of the lack of relevant and applicable indicators, the evaluation objectives and methods for decision-making of early design are proposed in this study. Finally, we conducted a case study to confirm the applicability of the process and method in practical design work.

\section{Methodology}

\subsection{BPO Workflow}

Architectural design is a very complex task that involves various design decisions with different aspects and levels of detail. Therefore, the entire design process is often divided into separate stages, each with different design issues, and decision-making is also made in such stages to gradually develop the architectural design. Design issues arising in the early process may be layout of plan, geometry of building mass, and opening location, all of which will affect building performance in different environmental terms.

The early-design BPO workflow in this manuscript demonstrates a two-step decisionmaking process. The design variables, the simulation conducted, and the evaluation indicators used in each step are shown in Figure 1. Focusing on wind field and thermal factors, solar-related assessments were conducted in the first step due to their speed and efficiency, while further considerations of ventilation and comfort were performed in the 
second step. Through multi-objective optimization (MOO), we analyzed each step and then obtained optimized design alternatives to assist with decision-making.

Step 1

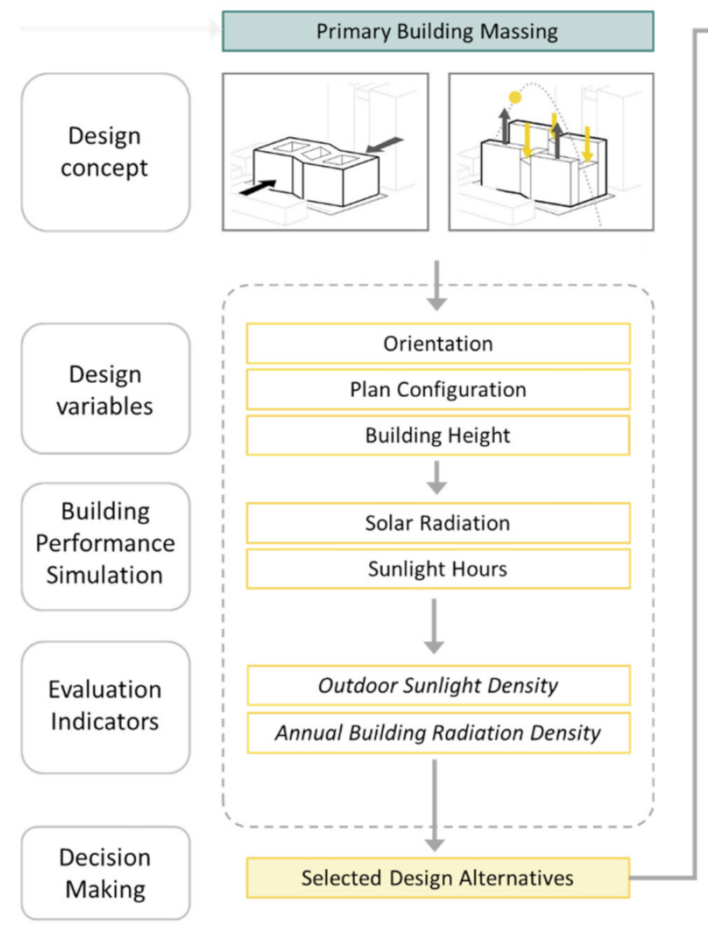

Step 2

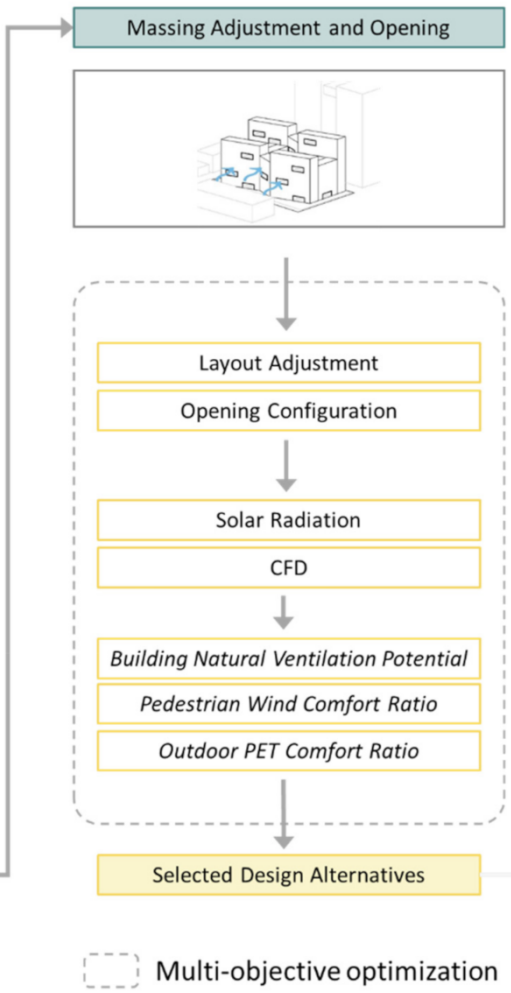

Figure 1. The BPO workflow for early design decision.

\subsection{Platform and Tools}

The proposed BPO workflow was established through Grasshopper, a visual programming language and environment that runs within the Rhinoceros 3D computer-aided design (CAD) application [45]. The detailed content of optimization workflow is shown in Figure 2, including parametric modeling, simulation setting, simulation operation, evaluation definition, multi-objective optimization, and result visualization.

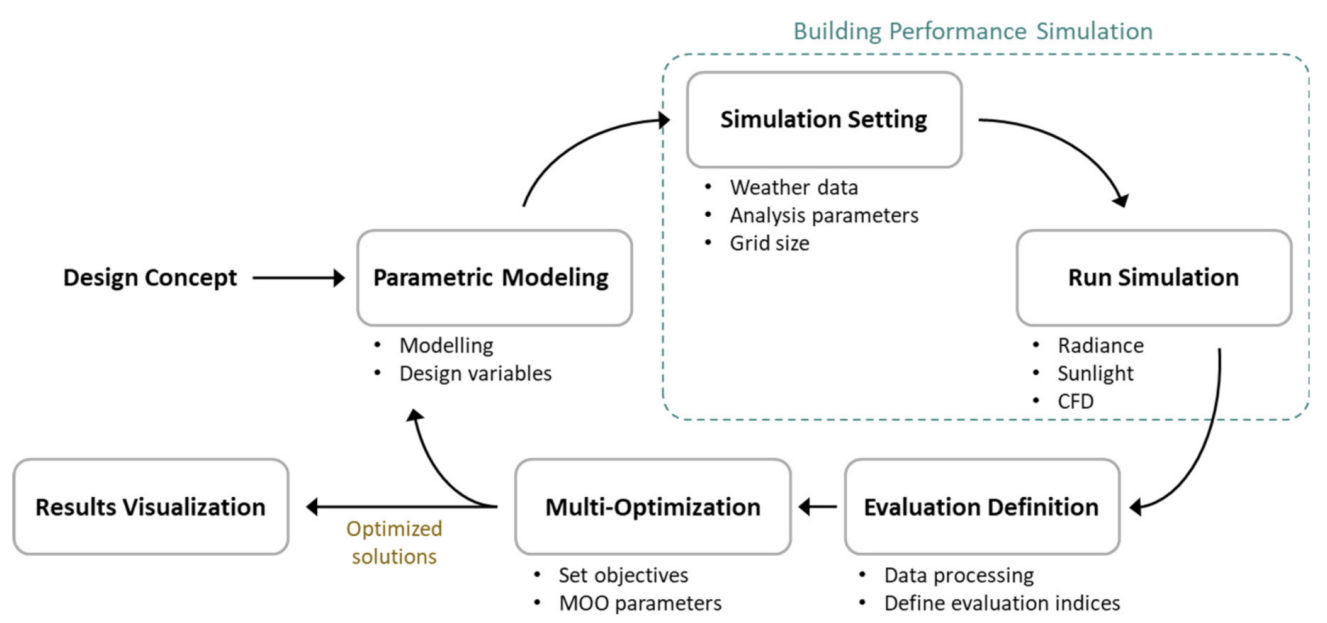

Figure 2. Detailed content of optimization workflow.

Building information and variables were modeled and controlled parametrically with the graphical algorithm editor Grasshopper. In step 1 of the solar-related assessment, 
we adopted Ladybug [46] for sunlight hour simulation and DIVA [47] for solar radiation simulation. In step 2, Flowdesigner [48] was adopted for wind field simulation, and Ladybug was again used for thermal comfort calculations to evaluate ventilation and thermal comfort. We then converted these simulation results into evaluation indicators and input them into the optimization tool Wallacei [49] for multi-objective optimization. Wallacei optimizes the design alternative using the Nondominated Sorting Genetic Algorithm II (NSGA-II) algorithm [50], which can weigh different goals in a limited time and find a solution with excellent performance [51,52].

\subsection{Evaluation Indicators}

In this section, we explain in detail the evaluation indicators used in the two steps. These indicators are all proposed to evaluate the overall performance of the building design.

\subsubsection{Step 1}

Solar radiation is the most significant factor affecting the environment in the microclimate [53]. The relationship between the sun and the massing of buildings has an interactive effect on both indoor and outdoor thermal energy performance. The evaluations in step 1 include Outdoor Sunlight Density and Annual Building Radiation Density.

- $\quad$ Outdoor Sunlight Density $\left(S U N \_D\right)$

The evaluation indicator of Outdoor Sunlight Density $\left(\mathrm{hr} / \mathrm{m}^{2}\right)$ is defined in the following equation:

$$
S U N \_D\left(h r / m^{2}\right)=\frac{\sum_{i=1}^{N} S U N h r_{i}}{N}
$$

where $N$ is the number of grids for simulation, and $S U N h r_{i}$ is the sunlight hours of each grid $(h r)$ obtained by simulation.

The sunlight density can vary according to the seasonal conditions or time periods being analyzed as different seasons have different expectations regarding sunlight density. For example, in the subtropical climate, SUN_D can be divided into SUN_D hot for the hot season and SUN_D cool for the cool season. In the hot season, SUN_D hot should be as small as possible, while in the cool season, a larger $S U N_{-} D_{\text {cool }}$ is better.

- Annual Building Radiation Density $\left(B R A D \_D\right)$

The evaluation indicator of Annual Building Radiation Density $\left(k W h / m^{2} \cdot y r\right)$ is defined in the equation below:

$$
\text { BRAD_D }\left(k W h / m^{2} \cdot y r\right)=\frac{\sum_{i=1}^{N} R A D_{i}}{A_{\text {floor }}}
$$

where $R A D_{i}$ is the annual cumulative radiation of each grid on the building envelope $(k W h / y r)$ obtained by simulation, and $A_{\text {floor }}$ is the total area of the building floor $\left(\mathrm{m}^{2}\right)$, which can be obtained by dividing the building volume by a fixed floor height in the early design phase.

In a subtropical climate, this index is considered to be as small as possible to avoid increasing indoor cooling load by excessive solar radiation.

\subsubsection{Step 2}

To ensure effective heat removal and air quality, the flow path required for natural ventilation should be considered and provided in the early stage of building design. In step 2, the ventilation and comfort of the design alternatives are further considered. In this stage, the workflow introduces airflow simulation, and the evaluations include Building Natural Ventilation Potential, Pedestrian Wind Comfort Ratio, and Outdoor PET Comfort Ratio. 


\section{- $\quad$ Building Natural Ventilation Potential (BNVP)}

Natural ventilation is one of the most important energy-saving technologies in passive building design. In climate areas with stable wind fields, using wind pressure to promote building ventilation is a suitable option. The general calculation method of ventilation rate $(Q)$ is shown in Equation (3). As in Equation (3), when the pressure difference $(\Delta P)$ is greater, the ventilation rate $(Q)$ is higher.

$$
Q=C_{d} A_{\text {opening }} \sqrt{\frac{2 \Delta P}{\rho}}
$$

where $Q$ is ventilation rate (unit), $C_{d}$ is flow coefficient (unit), $A_{\text {opening }}$ is the area of the opening $\left(m^{2}\right), \Delta P$ is the pressure difference between indoor and outdoor $(\mathrm{Pa})$, and $\rho$ is air density $\left(\mathrm{kg} / \mathrm{m}^{3}\right)$.

Because of the lack of interior information in early design, this study proposed calculating wind pressure differences to evaluate the building natural ventilation potential by setting up corresponding wind pressure sensor points on the windward and leeward sides of the building. The evaluation indicator of Building Natural Ventilation Potential (Pa) based on average wind pressure is defined in Equations (4) and (5). Since many sensor points are distributed in different locations, the overall ventilation performance is represented by their average value.

$$
\begin{gathered}
\Delta P_{j}=P_{i j}-P_{o j} \\
B N V P=\frac{\sum_{j=1}^{K}\left|\Delta P_{j}\right|}{K}
\end{gathered}
$$

where $\Delta P_{j}$ is the difference between windward and leeward wind pressure on the building $(\mathrm{Pa}), K$ is the number of pressure difference calculations, $P_{i j}$ is wind pressure on the windward side $(\mathrm{Pa})$, and $P_{o j}$ is wind pressure on the leeward side (Pa).

- Pedestrian Wind Comfort Ratio $\left(P W C_{R}\right)$

To create a favorable outdoor pedestrian activity space, pedestrian wind comfort should be carefully examined because it is related to the effect of wind on the comfort and safety of pedestrians and cyclists. An outdoor wind speed that is too low will cause stagnant wind and accumulate pollutants in the air. A wind speed that reaches $0.5 \mathrm{~m} / \mathrm{s}$ is considered to be able to effectively remove pollutants [54]. Furthermore, when the wind speed exceeds $3.3 \mathrm{~m} / \mathrm{s}$, which is equivalent to reaching Beaufort scale 3 , it is not recommended for pedestrians to be outdoors for extended periods of time. Therefore, we set a wind speed in the range of $0.5-3.3 \mathrm{~m} / \mathrm{s}$ is set as the pedestrian wind comfort zone. The evaluation indicator of Pedestrian Wind Comfort Ratio (\%) is defined by Equation (6).

$$
P W C_{R}=\frac{\sum_{j=1}^{N} V C_{j}}{N} \in[0,1], W_{j}=\left\{\begin{array}{c}
1,0.5 \leq V_{j} \leq 3.3 \\
0, V_{j}<0.5 \text { or } V_{j}>3.3
\end{array}\right.
$$

where $V_{j}$ is wind velocity of each grid in the site obtained from CFD simulation under prevailing wind condition (m/s), and $V C_{j}$ is 1 or 0 according to wind velocity value $V_{j}$.

$P W C_{R}$ represents the percentage of the area in the site where the wind velocity meets the pedestrian wind comfort zone standard. A higher $P W C_{R}$ value indicates a larger outdoor area of wind comfort and the overall better wind performance of the design.

- Outdoor PET Comfort Ratio $\left(\right.$ PETC $\left._{R}\right)$

Physiologically equivalent temperature (PET) is one of the most commonly used indicators for measuring thermal stress in outdoor spaces [28]. To examine the effect of building design on the thermal comfort of outdoor spaces, we adopted PET to develop the evaluation indicators for this study. According to a study of occupants' thermal comfort in 
the subtropical climate of Taiwan [55], a PET in the range of $26-30{ }^{\circ} \mathrm{C}$ is set as the outdoor thermal comfort zone. The evaluation indicator of Outdoor PET Comfort Ratio (\%) is defined in Equation (7).

PET is calculated using parameters under specific conditions (e.g., air temperature, air humidity, wind velocity, mean radiant temperature, and clothing and activity of humans at a specific time and position). To evaluate the performance of dynamic time and space, an evaluation time must be given (e.g., 10 a.m. to 3 p.m. on the 21 st of every month, a total of $60 \mathrm{~h}$ ). Based on the given times and wind velocities at different grid points, the PET values at different times and locations can be calculated, and $P E T C_{R}$ represents the comfort ratio at these times and positions.

$$
\operatorname{PETC}_{R}=\frac{\sum T C_{i j}}{N \times t} \in[0,1], T C_{i j}=\left\{\begin{array}{cc}
1, & 26 \leq T_{i j} \leq 30 \\
0, & T_{i j}<26 \text { or } T_{i j}>30
\end{array}\right.
$$

where $T_{i j}$ is the PET of each grid point and each given time, calculated by Ladybug $\left({ }^{\circ} \mathrm{C}\right)$, $T C_{i j}$ is 1 or 0 according to PET value $T_{i j}$, and $t$ is the number of hours of evaluation time.

\section{Case Study and Results}

\subsection{Case Description}

We applied the developed workflow to a public housing building design in Taichung, Taiwan, which has a humid subtropical climate. The description of the site is shown in Figure 3, and its area is $5716 \mathrm{~m}^{2}$. The housing is required to contain 270 households and has three types of households, as shown in Figure 4. As Figure 5a shows, this case took six buildings (building A-building F) to form three outdoor spaces for the basic concept. We then changed the geometries based on the concept building and the design methods, including plan distortion, height staggering, and building hollowing, as shown in Figure 5b.

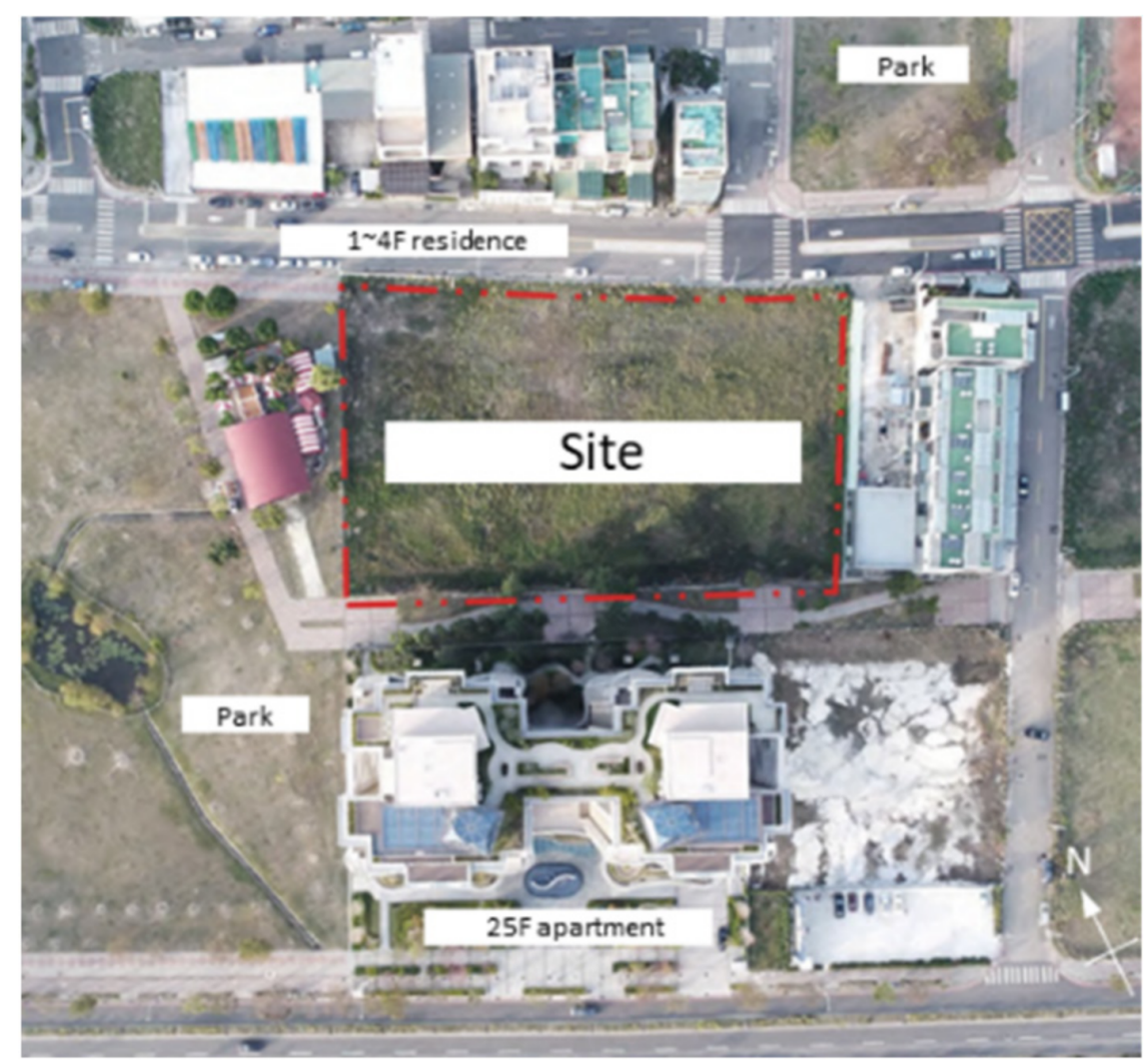

Figure 3. The site description. 

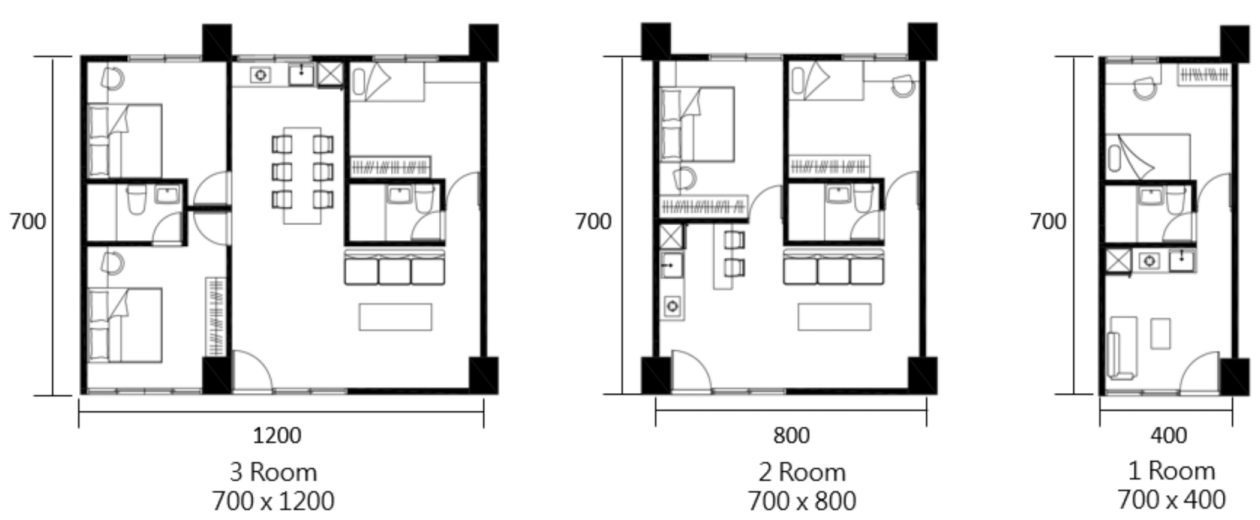

Figure 4. Household types and dimensions.

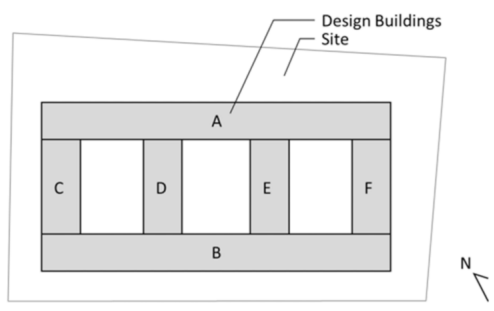

(a)

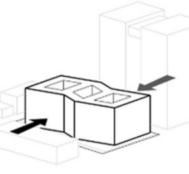

Geometry distorted

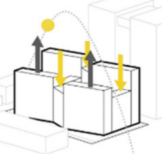

height staggered

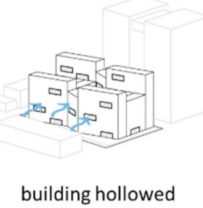

(b)

Figure 5. Concept building and design methods. (a) The composition concept of design building by 6 sub-buildings; (b) The three design methods to change building geometry.

The basic climate analyses of the site were conducted using 1998-2012 TMY3 hourly weather data. According to the hourly temperature distribution, May-October was considered the hot season (most hourly temperatures exceed $30^{\circ} \mathrm{C}$ ) and December-March the cool season (most hourly temperatures are below $18^{\circ} \mathrm{C}$ ). The two seasons have similar prevailing wind directions and wind velocities, as shown in Table 1.

Table 1. Seasonal division and climate information.

\begin{tabular}{ccccc}
\hline \multirow{2}{*}{ Months } & $\begin{array}{c}\text { Most } \mathbf{h} \\
\text { Temperature }\end{array}$ & \multicolumn{2}{c}{ Prevailing Wind } \\
\cline { 4 - 5 } & & $>30^{\circ} \mathrm{C}$ & Direction & Velocity \\
\hline Hot Season & $5-10$ & $<18^{\circ} \mathrm{C}$ & North & $2.13 \mathrm{~m} / \mathrm{s}$ \\
Cool Season & $12-3$ & & North & $2.15 \mathrm{~m} / \mathrm{s}$ \\
\hline
\end{tabular}

\subsection{Step 1: Primary Building Massing}

In step 1, the process focused on the optimization of primary building massing for better solar-related performance. We varied building massing alternatives by distorting the plan's geometry and staggering the height and assessed and optimized them using the indicators of Annual Building Radiation Density $\left(B R A D \_D\right)$, Outdoor Hot Season Sunlight Density $\left(S U N \_D_{h o t}\right)$, and Outdoor Cool Season Sunlight Density $\left(S U N \_D_{\text {cool }}\right)$.

\subsubsection{Design Variations}

The examples of distorted plan geometry are shown in Figure 6, which had a total of 90 variations. The examples of staggered building height are shown in Figure 7, which had a total of 96 variations. A total of 8640 building massing design options were included in step 1 . 


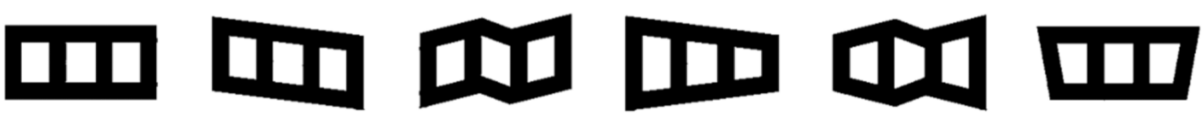

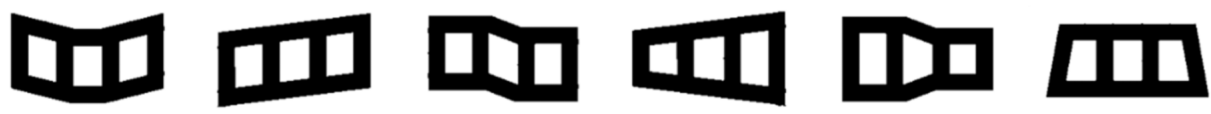

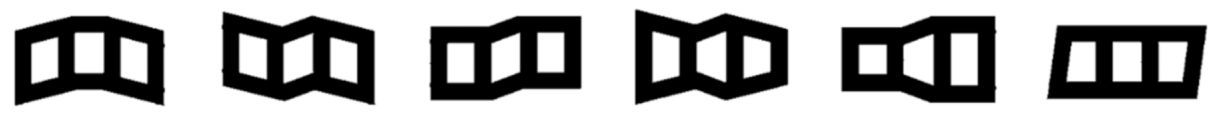

Figure 6. Examples of plan geometric variations.
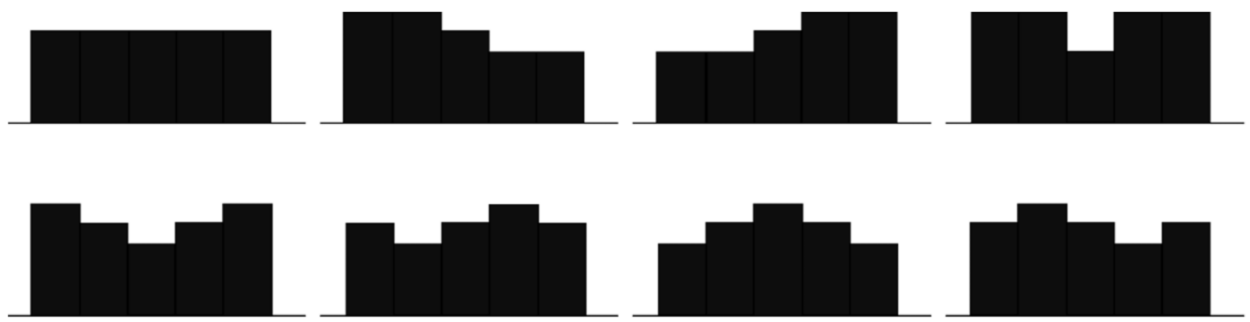

Figure 7. Examples of building height variations.

\subsubsection{Simulation and MOO Setting}

Sunlight hour simulation and solar radiation simulation must be performed before calculating the evaluation indicators Outdoor Sunlight Density and Annual Building Radiation Density. To calculate SUN_D hot and SUN_D cool, we used the Ladybug tool according to the different months of the hot season and cool season to simulate cumulative sunlight hours.

To calculate $B R A D \_D$, we carried out annual cumulative radiation simulation of building envelops with the DIVA tool. In the DIVA simulation, the ground reflectivity was set to 0.2 , and the building reflectivity was set to 0.8 . For quick evaluation in early design, the simulation quality was set to low, which represents a simple reflection simulation.

We adopted the Wallacei tool to optimize the evaluation indicators SUN_D hot, SUN_D ${ }_{\text {cool }}$, and $B R A D \_D$ through evolutionary algorithms. The crossover probability was set to 0.9 and mutation probability to $1 / 29$, where 29 was the number of genes. According to the NSGAII algorithm adopted by Wallacei, Pareto-optimal solutions can be obtained in the MOO process and provided to architects for design decisions [35]. Since the evaluation indicator $S U N \_D_{\text {cool }}$ should be as large as possible, 1 was divided by $S U N \_D_{\text {cool }}$ to optimize the design solutions that minimized $S U N \_D_{h o t}, 1 / S U N \_D_{\text {cool }}$, and BRAD_D.

\subsubsection{Results of Step 1}

We set the generation size to 40 , and there were 20 generations, meaning a total of 800 optimization iterations were proceeded to optimize. The optimization process took about $72 \mathrm{~h}$, which is considered acceptable in the early design. Table 2 shows the low and high value results and the performance advance of three solar-related evaluation indicators. Figure 8 shows the scatter plots of all design alternatives and Pareto solutions.

Table 2. Results of value and performance advance (all 800 variations).

\begin{tabular}{ccccc}
\hline Indicators & Low Value & High Value & \multicolumn{2}{c}{ Max Performance Advance } \\
\hline$B R A D \_D\left(\mathrm{kWh} / \mathrm{m}^{2} \cdot \mathrm{yr}\right)$ & 417.52 & 467.57 & 50.05 & $12.0 \%$ \\
\hline$S U N \_D_{\text {hot }}\left(\mathrm{h} / \mathrm{m}^{2}\right)$ & 841.70 & 1042.54 & 200.84 & $23.9 \%$ \\
\hline$S U N \_D_{\text {cool }}\left(\mathrm{h} / \mathrm{m}^{2}\right)$ & 283.77 & 354.11 & 70.34 & $24.8 \%$ \\
\hline
\end{tabular}




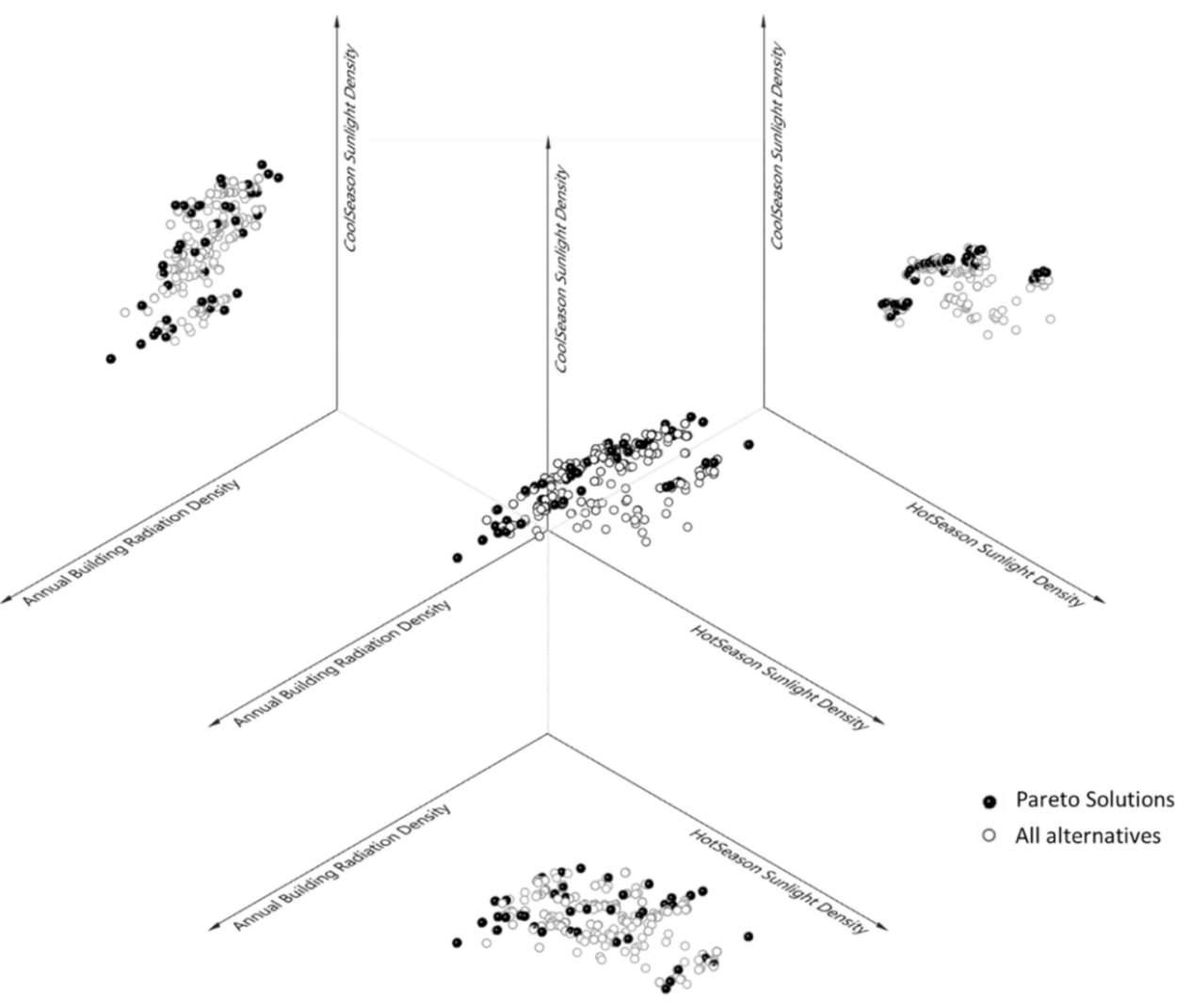

Figure 8. The scatter plots of all 800 alternatives and Pareto solutions.

The step 1 optimization process obtained 40 Pareto solutions, and the performance of each Pareto solution in the three evaluation indicators is shown in Figure 9. The design solutions were then sorted according to the performance results of BRAD_D, SUN_D hot and SUN_D $D_{\text {cool }}$, respectively. The rankings are depicted in color variation, where green represents most in line with the objective performance, and orange represents farthest from the objective. In the ranking of the indicators, the top 5 of the 40 design solutions are marked in bold.

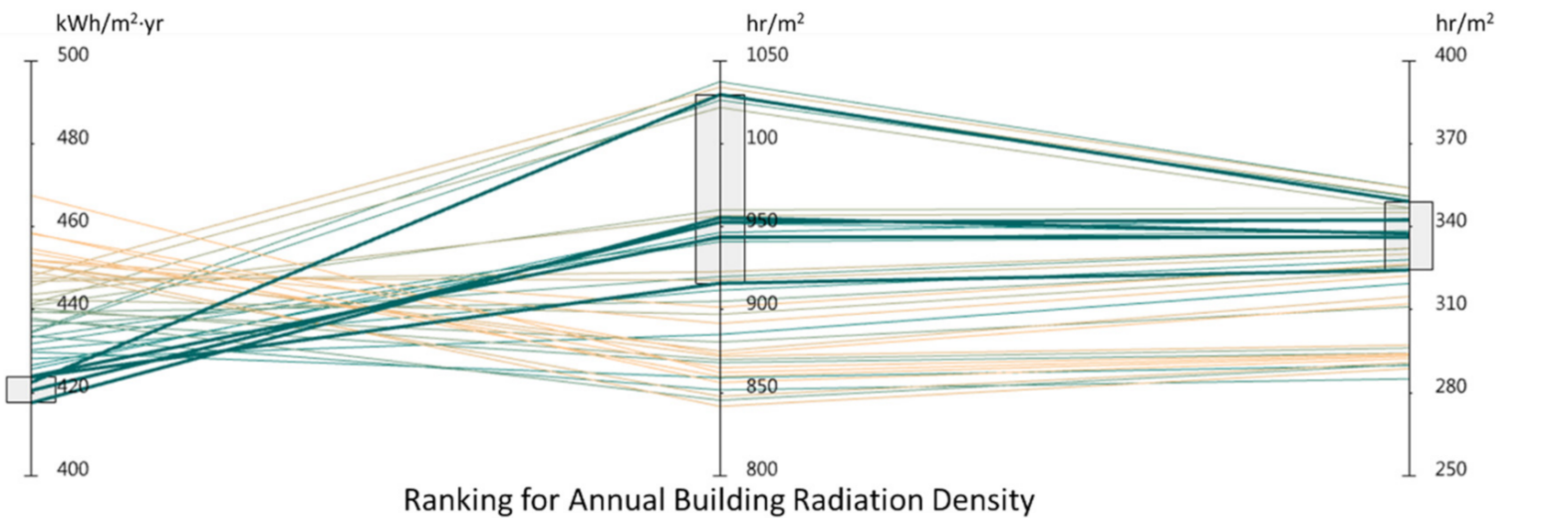

(a)

Figure 9. Cont. 


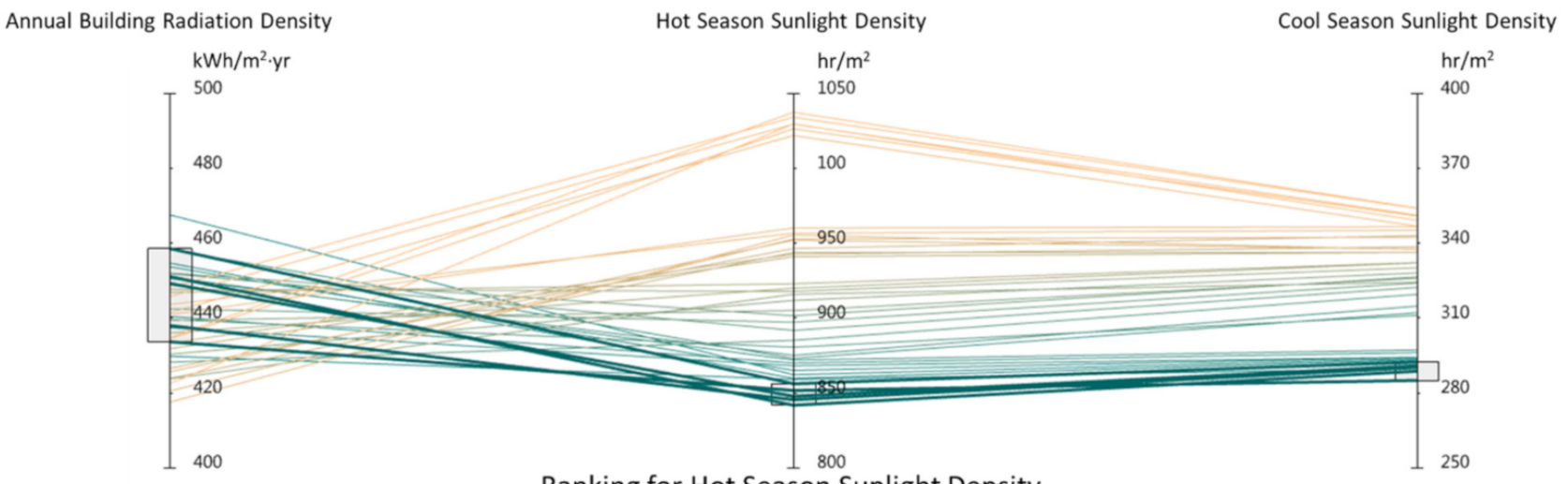

(b)

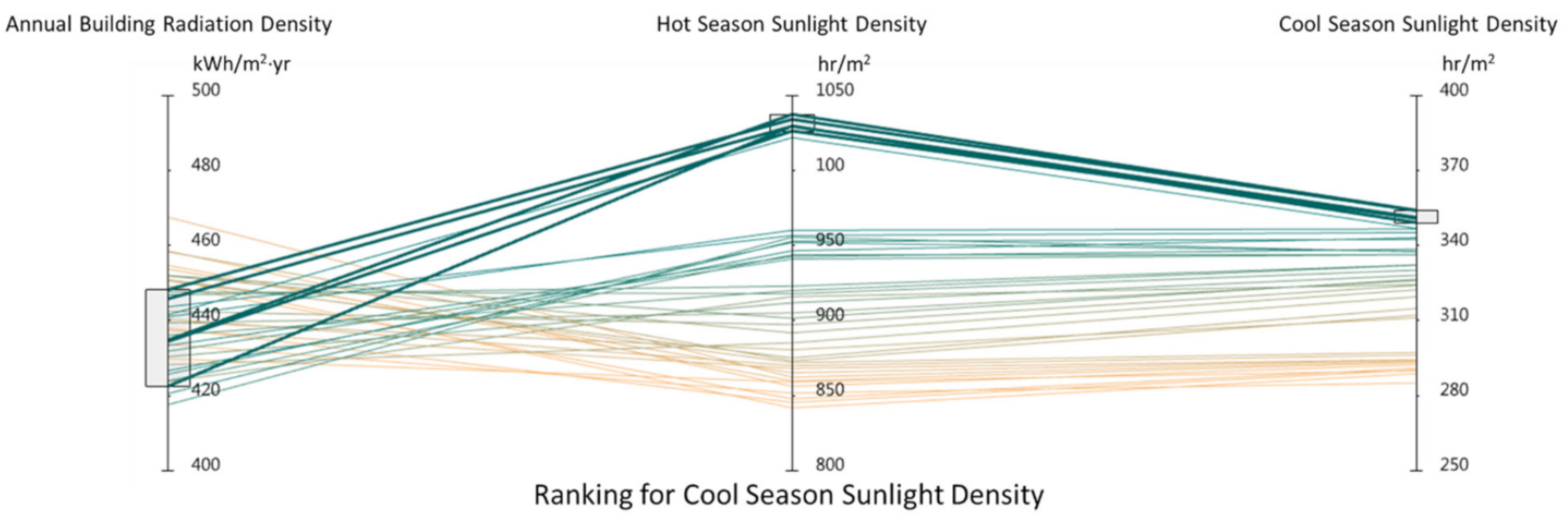

(c)

Figure 9. The evaluation indicator performance of each Pareto solution (step 1). (a) The ranking based on $B R A D \_D$; (b) The ranking based on $S U N_{-} D_{\text {hot }} ;(\mathbf{c})$ The ranking based on $S U N_{-} D_{\text {cool }}$.

The results of Figure 9 show that obtaining a design solution that fully meets expectations is not easy, as the results of the three indicators are conflicting. When one of the indicators performs well, at least one of the other indicators needs improvement. For example, although the top five designs in the ranking of annual building radiation density are in line with expectations with regard to cool season sunlight density, they had very poor performance in the sunlight density of the hot season. In particular, the values of sunlight density in the hot and cool seasons usually increase and decrease simultaneously; thus, a trade-off between these two indicators is necessary for decision making.

To assist with the decision-making, we then used k-means clustering [56] to divide the Pareto solutions into three clusters, as shown in Figure 10. Cluster A includes the solutions with poor performance of the hot season and better performance of the cool season. Cluster $B$ includes the solutions with better performance of the hot season and poor performance of the cool season. Cluster $C$ includes the solutions that have moderate performance in both the hot and cool seasons. The results of Cluster A, Cluster B, and Cluster C in the different evaluation indicators are shown in Figure 11. The results show no significant difference between the three clusters in terms of radiation density. Through these results and design layouts (e.g., the plan layouts in Figure 12), the designers can determine solutions based on environmental performance and preferences. 


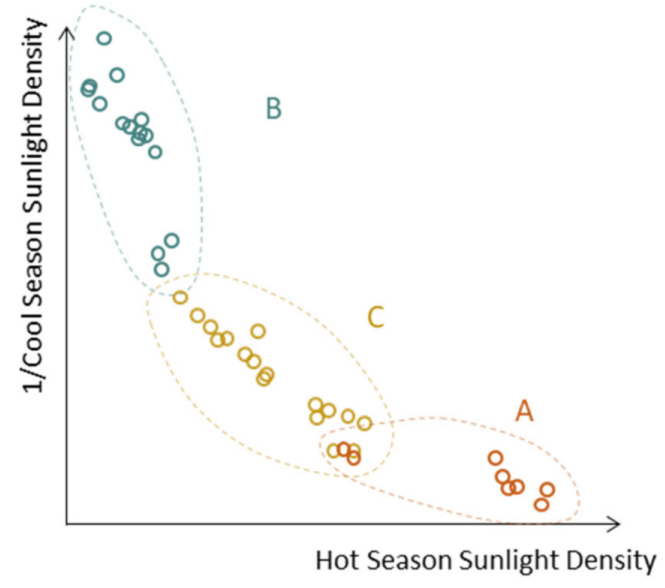

(a)

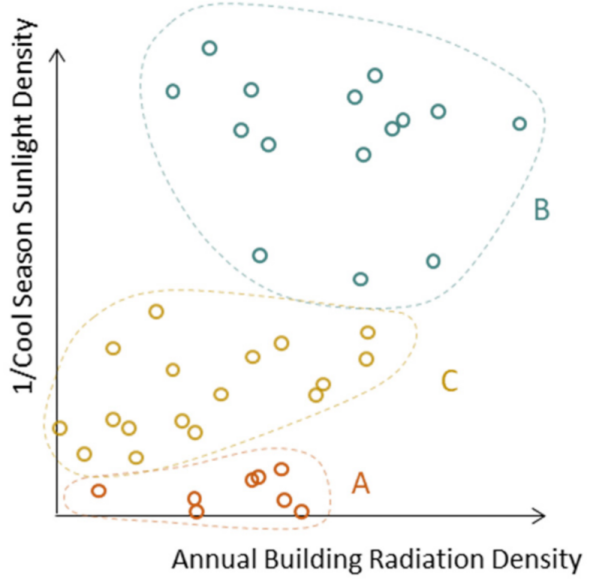

(b)

Figure 10. Clusters of solutions by k-means clustering (step 1). (a) The cluster distribution based on plane of SUN_D hot and $1 / S U N \_D_{\text {cool }} ;(\mathbf{b})$ The cluster distribution based on plane of BRAD_D and $1 / S U N \_D_{\text {cool }}$.

(a) Annual Building Radiation Density

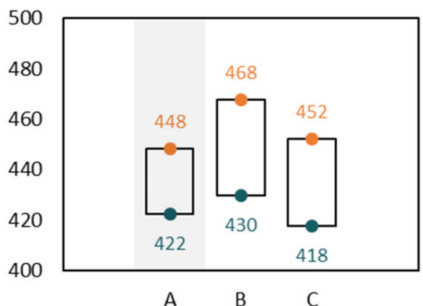

(b) Hot Season Sunlight Density

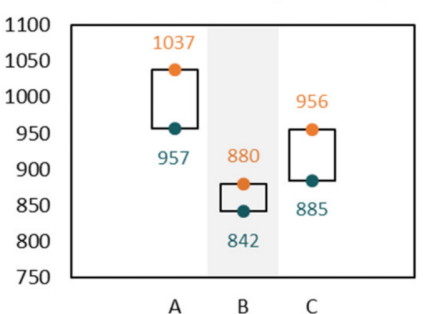

(c) Cool Season Sunlight Density

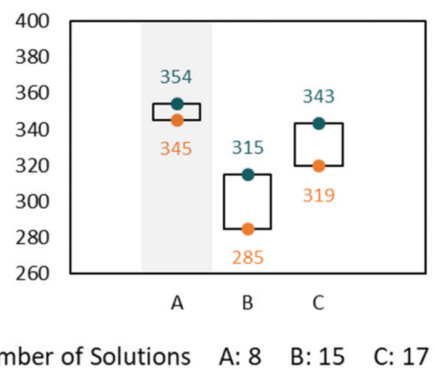

Figure 11. Performance of clusters regarding different indicators (step 1). (a) Performance on $B R A D \_D ;(\mathbf{b})$ Performance on $S U N \_D_{h o t} ;$ (c) Performance on SUN_D $D_{\text {cool }}$.

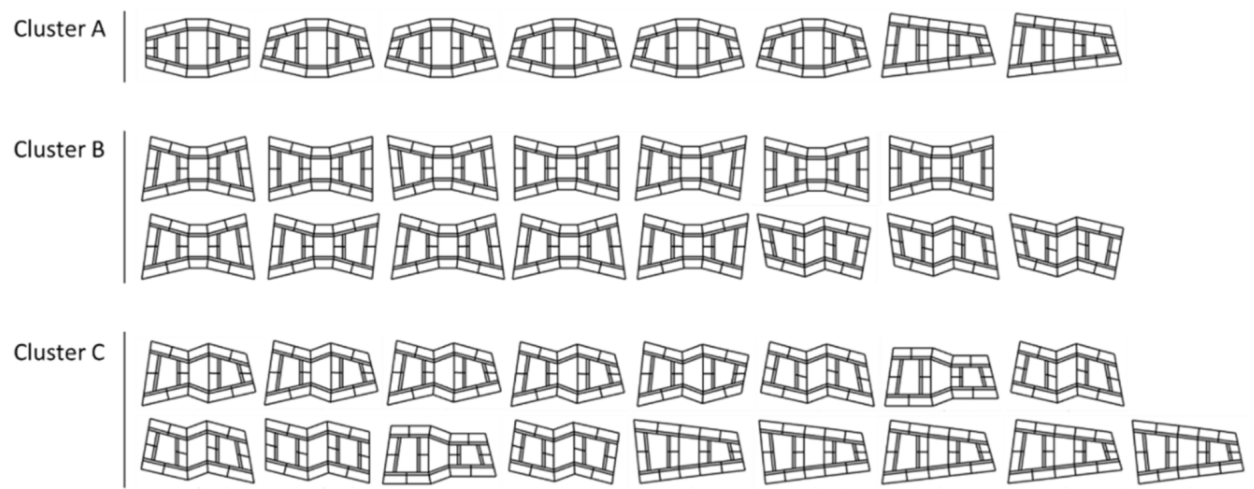

Figure 12. The plan layouts of clusters A, B, and C.

The results show that Cluster A contains the best performance of two indicators $\left(B R A D \_D\right.$ and SUN_ $\left.D_{\text {cool }}\right)$. Therefore, this manuscript has selected a solution in Cluster A as demonstration to hollow the building and evaluate wind and comfort in step 2. It is worth noting that the solution decisions in this part would predictably vary according to the project objectives or preferences of architects or owners. The selected solution is A-16 of which building description and performance are shown in Figure 13. It can be found that A-16 is almost the best solution in $B R A D \_D$ and $S U N \_D_{\text {cool }}$, but quite poor performance in $S U N \_D_{\text {hot }}$. 

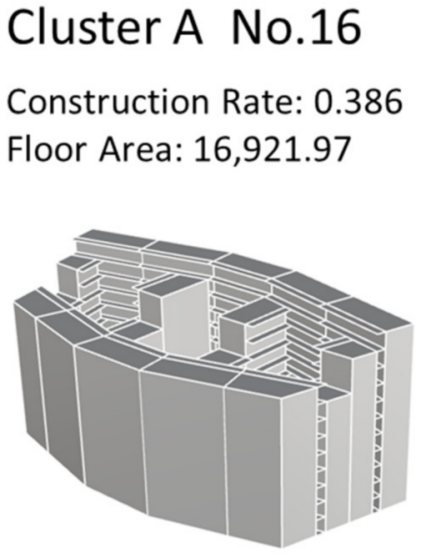

BRAD_D

Value: 422.4

Ranking: 15
SUN_D $D_{\text {hot }}$
Value: $1,029.7$
Ranking: 759

SUN_D $D_{\text {cool }}$

Ranking: 759 Ranking: 49

Figure 13. Building description and performance of A-16.

\subsection{Step 2: Massing Adjustment and Opening}

In step 2, the building massing of A-16 was hollowed by several openings, and we performed the optimal process to facilitate design solutions that consider ventilation and comfort performance. The evaluation indicators optimized in this step are Building Natural Ventilation Potential $(B N V P)$, Pedestrian Wind Comfort Ratio $\left(P W C_{R}\right)$, and Outdoor PET Comfort Ratio $\left(\right.$ PETC $\left._{R}\right)$.

\subsubsection{Subsubsection}

The building alternatives are varied by hollowing the building massing of A-16. The examples of the hollowed building are shown in Figure 14, with a total of 640 design options in this step.
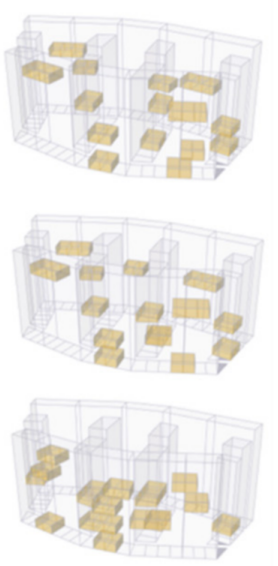
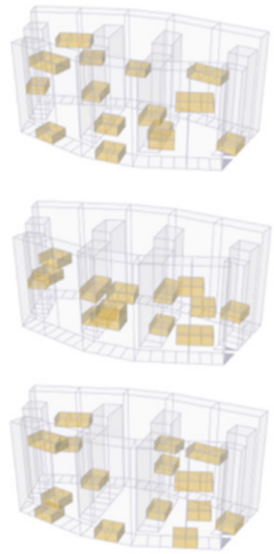
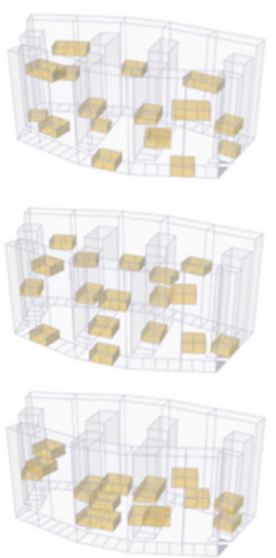
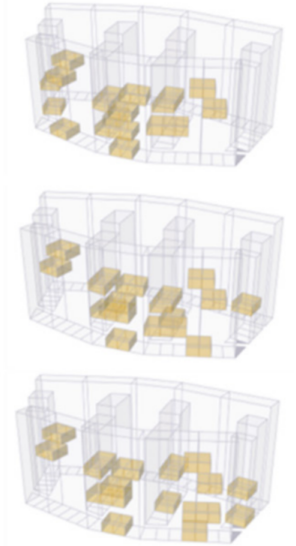

Openings

Figure 14. Examples of building hollowed variations.

\subsubsection{Simulation and MOO Setting}

We first conducted CFD simulation through Flowdesigner in Grasshopper to evaluate Building Natural Ventilation Potential $(B N V P)$, Pedestrian Wind Comfort Ratio $\left(P W C_{R}\right)$, and Outdoor PET Comfort Ratio $\left(P E T C_{R}\right)$. The standard $k-\varepsilon$ turbulent model was selected in the simulation. The CFD results were then used to calculated $B N V P$ and $P W C_{R}$. The simulation results were further input into Ladybug to analyze the PET values.

As calculation of PET is based on specific times and locations, to evaluate the $P_{E T C}$, the time and area to be analyzed must be defined first. In this manuscript, the analysis area was divided by each $2 \times 2 \mathrm{~m}$ grid, for a total of 1002 analysis grid points. The analyzed 
time was a total of $48 \mathrm{~h}$, as shown in Table 3. The information and sources that PET required are shown in Table 4.

Table 3. Analyzed time for PET calculation.

\begin{tabular}{cccc}
\hline & Months & Day & Time \\
\hline Hot Season & $5-10$ & 21 & $7-10,15-18$ \\
Cool Season & $12-3$ & 21 & $13-16$ \\
\hline & & Total & $48 \mathrm{~h}$ \\
\hline
\end{tabular}

Table 4. Information and sources for PET calculation in Ladybug.

\begin{tabular}{ccc}
\hline Parameters & Data Source & Change of Value \\
\hline Temperature & Weather file (.epw) & Values based on time \\
Humidity & Weather file (.epw) & Values based on time \\
Wind Speed & CFD simulation & Values based on time/grid \\
Sky Cover & Weather file (.epw) & Values based on time \\
Solar Radiation & Ladybug Tools & Values based on time/grid \\
\hline
\end{tabular}

Since these three evaluation indicators representing degree of potential and comfort should be as large as possible, for the objective functions for optimization, we divided 1 by $B N V P, P W C_{R}$, and $P E T C_{R}$. We then used The Wallacei tool to find the design solutions with minimal $1 / B N V P, 1 / P W C_{R}$, and $1 / P E T C_{R}$.

\subsubsection{Results of Step 2}

We set the generation size to 30 , and there are three generations, meaning a total of 90 optimization iterations were proceeded to optimize. The optimization process took about $23.5 \mathrm{~h}$. Table 5 shows the low and high value results and the performance advance of ventilation and comfort evaluation indicators.

Table 5. Results of value and performance advance (all 90 variations).

\begin{tabular}{ccccc}
\hline Indicators & Low Value & High Value & \multicolumn{2}{c}{ Max Performance Advance } \\
\hline$B N V P(\mathrm{~Pa})$ & 2.37 & 2.68 & 0.31 & $13.0 \%$ \\
$P W C_{R}(\%)$ & 39.5 & 76.7 & 37.2 & $94.1 \%$ \\
$P E T C_{R}(\%)$ & 55.5 & 58.6 & 3.1 & $5.6 \%$ \\
\hline
\end{tabular}

The step 2 optimization process obtained 30 Pareto solutions, and the performance of each pareto solution in the three evaluation indicators is shown in Figure 15. The design solutions are sorted according to the performance results of $B N V P, P W C_{R}$, and $P E T C_{R}$, respectively. In the ranking of the indicators, the top three of the 30 design solutions are marked in bold. The results show that the design solutions with better BNVP performance have poorer $P W C_{R}$ performance and vice versa. The design solutions with better $P E T C_{R}$ performance also perform better in $B N V P$, while performing moderately in $P W C_{R}$.

As before, we also conducted k-means clustering in step 2. As shown in Figure 16, Cluster a includes the solutions with better performance in $B N V P$ and $P E T C_{R}$ but poorer in $P W C_{R}$. Cluster b includes the solutions with better performance in $P W C_{R}$ but poorer in $B N V P$ and $P E T C_{R}$. Cluster $c$ includes the solutions with better performance in $B N V P$ but poorer in $P W C_{R}$ and $P E T C_{R}$. The results of Cluster a, Cluster b, and Cluster $\mathrm{c}$ in different evaluation indicators are shown in Figure 17. 


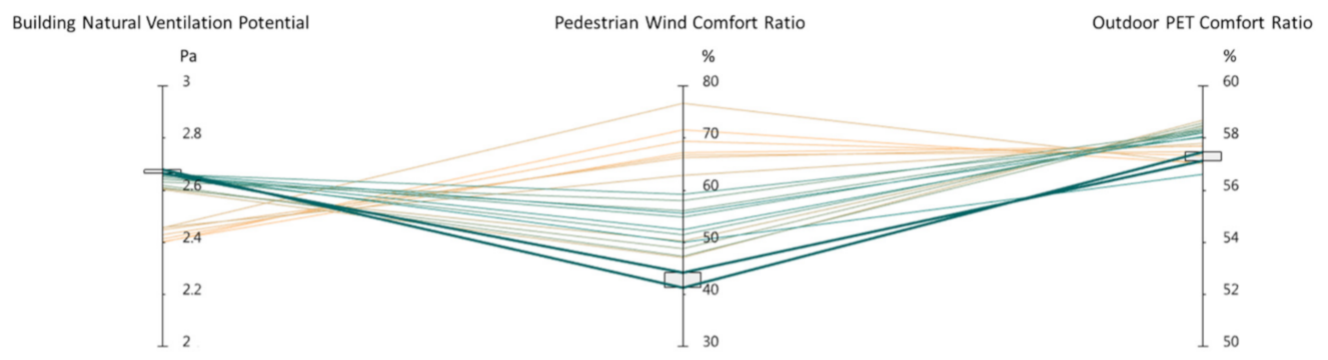

Ranking for Building Natural Ventilation Potential

(a)

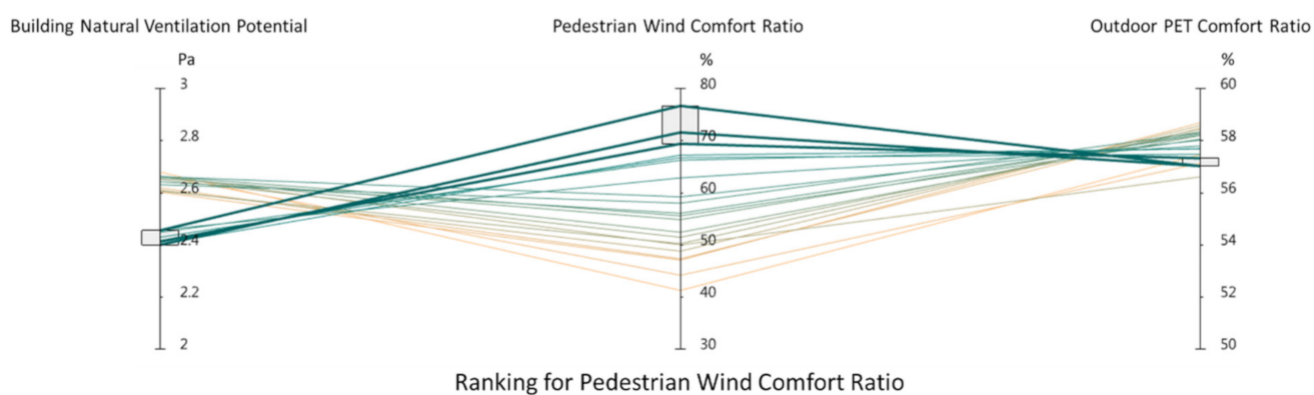

(b)

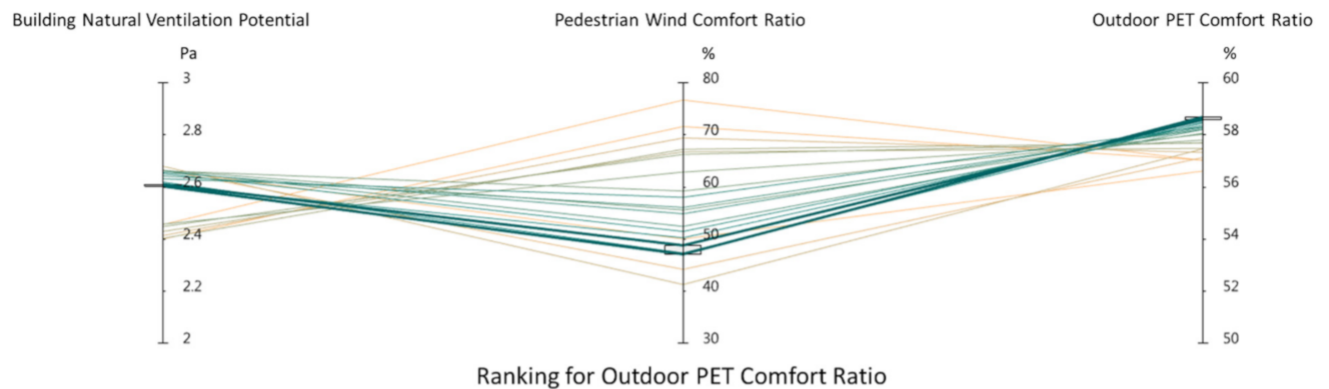

(c)

Figure 15. The evaluation indicator performance of each Pareto solution (step 2). (a) The ranking based on $B N V P ;(\mathbf{b})$ the ranking based on $P W C_{R} ;(\mathbf{c})$ the ranking based on $P E T C_{R}$.

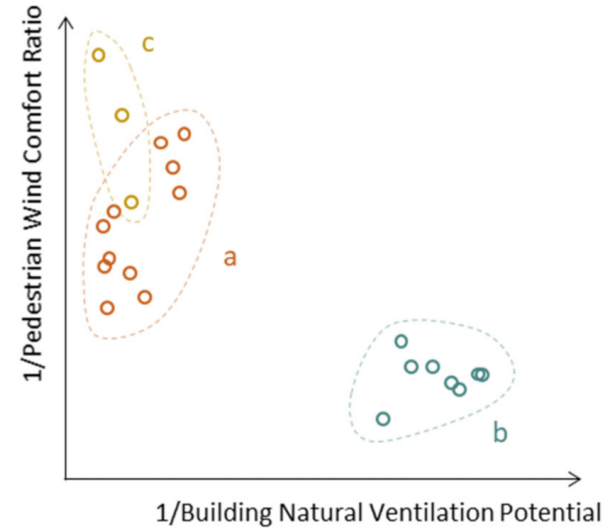

(a)

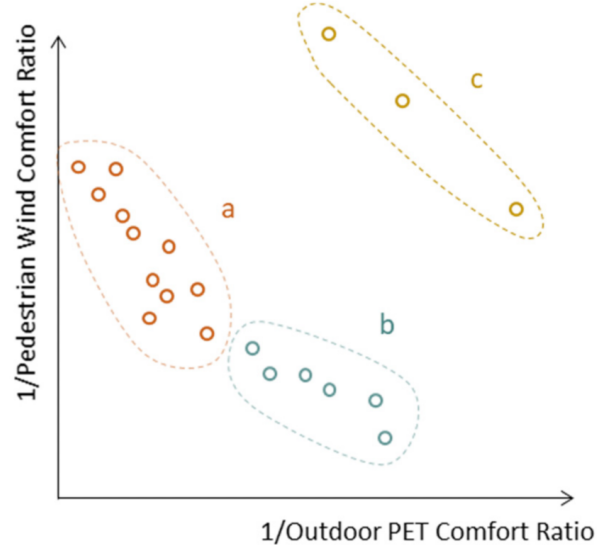

(b)

Figure 16. Clusters of solutions by k-means clustering (step 2). (a) The cluster distribution based on plane of $1 / B N V P$ and $1 / P W C_{R} ;(\mathbf{b})$ The cluster distribution based on plane of $1 / P E T C_{R}$ and $1 / P W C_{R}$. 
(a) Natural Ventilation Potential

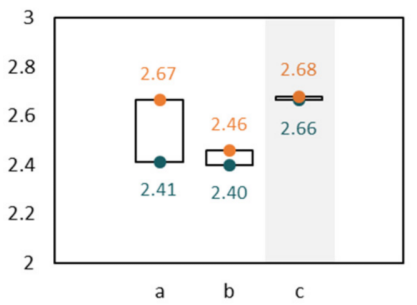

(b) Pedestrian Wind Comfort Ratio

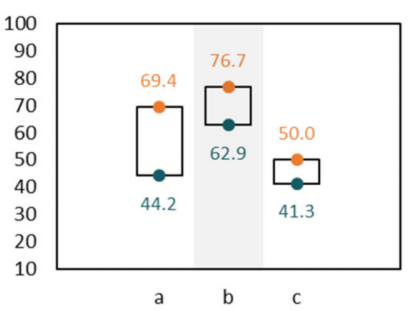

(c) Outdoor PET Comfort Ratio

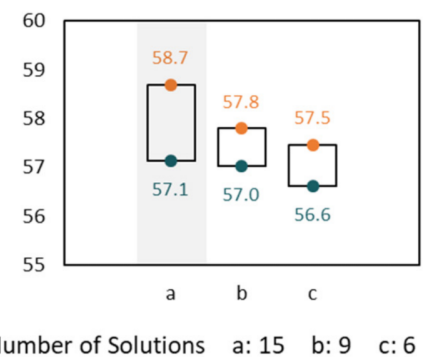

Figure 17. Performance of clusters on different indicators (step 2). (a) Performance on BNVP; (b) Performance on $P W C_{R} ;$ (c) Performance on $P E T C_{R}$.

According to the results, when the architect prioritizes the building ventilation potential, the solutions in Cluster $\mathrm{c}$ would be chosen; the solutions in Cluster b would be chosen when the architect is most concerned about the building's outdoor space comfort; and if the architect would like solutions with more comprehensive performance, the solutions in Cluster a may be their focus for development solutions for the next design stage.

\section{Discussion and Conclusions}

With the development of various building performance simulation tools, applying these tools to ensure advanced building design performance in the design process has become a popular trend. For the huge potential with regard to enhancing energy efficiency and the comfort and health of occupants, wind environment and thermal comfort assessments have great relevance with building geometry and ought to be evaluated as early as possible. Assessing wind and thermal topics in early design has two main barriers: a lack of evaluation methods for overall building performance and a clear evaluation process. In this manuscript, evaluation methods were suggested, and the workflow based on BPO was proposed, with the $\mathrm{BPO}$ workflow demonstrated by a case study to display the process in detail.

The results showed that the proposed evaluation methods produced evident performance results of buildings that allow architects to easily understand and compare alternatives. Furthermore, these evaluation indicators include conflictive items, providing the workflow with well-defined optimization objectives to facilitate trade-off Pareto solutions. Since the characteristics of architectural design largely depend on the designer's preferences and decisions, the focus of this manuscript was more on assisting with decision-making rather than the design results. For example, in the BPO workflow demonstration in Section 3, the optimized results are appropriately analyzed and visualized, which is identified to effectively help architects with determining design solutions and making decisions.

Although climatic conditions and case-limited design variations in this manuscript resulted in slight differences of some evaluation indicators, a greater extent of performance differences could be expected when the workflow is used in cases with greater design variations (e.g., larger massing transforms). The evaluation indicators used in this study (e.g., comfort zone of the wind velocity and PET value) are largely based on subtropical climate conditions. The comfort zone under different conditions (e.g., climate, population, or preference) would likely differ; therefore, these indicators should be adjusted according to design cases.

In general, the workflow proposed makes evaluating the wind and thermal environment and obtaining optimized design solutions more feasible in the limited time of early design. Moreover, the proposed overall performance indicators and visualization techniques can assist architects with their understanding and decision-making based on the simulation results. These efforts can thus facilitate the generation of performance-based buildings and create a healthier and more energy efficient environment. 
Author Contributions: Conceptualization, C.-H.L., M.-Y.C. and Y.-S.T.; methodology, C.-H.L. and M.-Y.C.; software, M.-Y.C.; validation, C.-H.L. and M.-Y.C.; formal analysis, C.-H.L.; data curation, M.-Y.C.; writing—original draft preparation, C.-H.L.; writing—review and editing, Y.-S.T.; visualization, C.-H.L. and M.-Y.C.; supervision, Y.-S.T. All authors have read and agreed to the published version of the manuscript.

Funding: This research was supported by Ministry of Science and Technology (110-2221-E-006-070).

Conflicts of Interest: The authors declare no conflict of interest.

\section{References}

1. Tian, Z.; Zhang, X.; Jin, X.; Zhou, X.; Si, B.; Shi, X. Towards adoption of building energy simulation and optimization for passive building design: A survey and a review. Energy Build. 2018, 158, 1306-1316. [CrossRef]

2. Hensen, J.L.M.; Lamberts, R. (Eds.) Building Performance Simulation for Design and Operation, 2nd ed.; Routledge: London, UK, 2019. [CrossRef]

3. Basic, S.; Hollberg, A.; Galimshina, A.; Habert, G. A design integrated parametric tool for real-time Life Cycle AssessmentBombyx project. IOP Conf. Series Earth Environ. Sci. 2019, 323, 012112. [CrossRef]

4. Zhao, Y.; Ducharne, A.; Sultan, B.; Braconnot, P.; Vautard, R. Estimating heat stress from climate-based indicators: Present-day biases and future spreads in the CMIP5 global climate model ensemble. Environ. Res. Lett. 2015, 10, 084013. [CrossRef]

5. Abdel-Ghany, A.M.; Al-Helal, I.M.; Shady, M.R. Human Thermal Comfort and Heat Stress in an Outdoor Urban Arid Environment: A Case Study. Adv. Meteorol. 2013, 2013, 1-7. [CrossRef]

6. De Oliveira, C.C.; Rupp, R.F.; Ghisi, E. Influence of environmental variables on thermal comfort and air quality perception in office buildings in the humid subtropical climate zone of Brazil. Energy Build. 2021, 243, 110982. [CrossRef]

7. Haase, M.; Amato, A. An investigation of the potential for natural ventilation and building orientation to achieve thermal comfort in warm and humid climates. Sol. Energy 2009, 83, 389-399. [CrossRef]

8. Cheng, V.; Ng, E.; Chan, C.; Givoni, B. Outdoor thermal comfort study in a sub-tropical climate: A longitudinal study based in Hong Kong. Int. J. Biometeorol. 2011, 56, 43-56. [CrossRef]

9. Chen, Y.; Tong, Z.; Malkawi, A. Investigating natural ventilation potentials across the globe: Regional and climatic variations. Build. Environ. 2017, 122, 386-396. [CrossRef]

10. Etheridge, D. Natural Ventilation of Buildings; John Wiley \& Sons: Chichester, UK, 2011. [CrossRef]

11. Mishra, A.K.; Ramgopal, M. A thermal comfort field study of naturally ventilated classrooms in Kharagpur, India. Build. Environ. 2015, 92, 396-406. [CrossRef]

12. Kim, J.; de Dear, R. Impact of different building ventilation modes on occupant expectations of the main IEQ factors. Build. Environ. 2012, 57, 184-193. [CrossRef]

13. Garde, F.; Ottenwelter, E.; Bornarel, A. Integrated Building Design in Tropical Climates: Lessons Learned from the ENERPOS Net Zero Energy Building. ASHRAE Trans. 2012, 118, 81-89.

14. Rodriguez-Ubinas, E.; Montero, C.; Porteros, M.; Vega, S.; Navarro, I.; Castillo-Cagigal, M.; Matallanas, E.; Gutiérrez, A. Passive design strategies and performance of Net Energy Plus Houses. Energy Build. 2014, 83, 10-22. [CrossRef]

15. Yang, W.; Zhang, G. Thermal comfort in naturally ventilated and air-conditioned buildings in humid subtropical climate zone in China. Int. J. Biometeorol. 2007, 52, 385-398. [CrossRef]

16. Carlucci, S.; Pagliano, L. A review of indices for the long-term evaluation of the general thermal comfort conditions in buildings. Energy Build. 2012, 53, 194-205. [CrossRef]

17. ASHRAE. Standard 62.1-2013 Ventilation for Acceptable Indoor Air Quality; American Society of Heating, Refrigerating and Air-Conditioning Engineers, Inc.: Atlanta, GA, USA, 2013; p. 40.

18. Awbi, H. Ventilation of Buildings; Routledge: London, UK, 2002.

19. Xing, H.; Hatton, A.; Awbi, H. A study of the air quality in the breathing zone in a room with displacement ventilation. Build. Environ. 2001, 36, 809-820. [CrossRef]

20. Wang, B.; Malkawi, A. Design-based natural ventilation evaluation in early stage for high performance buildings. Sustain. Cities Soc. 2019, 45, 25-37. [CrossRef]

21. Isyumov, N.; Davenport, A.G. The ground level wind environment in built-up areas. In Proceedings of the 4th International Conference on Wind Effects on Buildings and Structures, Heathrow, London, UK; 1975; pp. 403-422.

22. Lawson, T. The widn content of the built environment. J. Wind Eng. Ind. Aerodyn. 1978, 3, 93-105. [CrossRef]

23. Melbourne, W. Criteria for environmental wind conditions. J. Wind Eng. Ind. Aerodyn. 1978, 3, 241-249. [CrossRef]

24. Willemsen, E.; Wisse, J.A. Design for wind comfort in The Netherlands: Procedures, criteria and open research issues. J. Wind Eng. Ind. Aerodyn. 2007, 95, 1541-1550. [CrossRef]

25. Du, Y.; Mak, C.M.; Kwok, K.; Tse, K.-T.; Lee, T.-C.; Ai, Z.; Liu, A.J.; Niu, J. New criteria for assessing low wind environment at pedestrian level in Hong Kong. Build. Environ. 2017, 123, 23-36. [CrossRef]

26. Enescu, D. A review of thermal comfort models and indicators for indoor environments. Renew. Sustain. Energy Rev. 2017, 79, 1353-1379. [CrossRef] 
27. Fantozzi, F.; Rocca, M. An Extensive Collection of Evaluation Indicators to Assess Occupants' Health and Comfort in Indoor Environment. Atmosphere 2020, 11, 90. [CrossRef]

28. Höppe, P. The physiological equivalent temperature-a universal index for the biometeorological assessment of the thermal environment. Int. J. Biometeorol. 1999, 43, 71-75. [CrossRef] [PubMed]

29. Broede, P.; Fiala, D.; Blazejczyk, K.; Holmér, I.; Jendritzky, G.; Kampmann, B.; Tinz, B.; Havenith, G. Deriving the operational procedure for the Universal Thermal Climate Index (UTCI). Int. J. Biometeorol. 2011, 56, 481-494. [CrossRef]

30. Pickup, J.; de Dear, R. An outdoor thermal comfort index (OUT_SET ${ }^{*}$ )-part I-the model and its assumptions. In Biometeorology and Urban Climatology at the Turn of the Millennium; de Dear, R.J., Kalma, J.D., Oke, T.R., Auciliems, A., Eds.; WMO: Geneva, Swizterland, 2000; pp. 279-283.

31. Matzarakis, A.; Amelung, B. Physiological Equivalent Temperature as Indicator for Impacts of Climate Change on Thermal Comfort of Humans. In Seasonal Forecasts, Climatic Change and Human Health; Springer Science and Business Media: Berlin, Germany, 2008; pp. 161-172.

32. Blazejczyk, K.; Jendritzky, G.; Bröde, P.; Fiala, D.; Havenith, G.; Epstein, Y.; Psikuta, A.; Kampmann, B. An introduction to the Universal Thermal Climate Index (UTCI). Geogr. Pol. 2013, 86, 5-10. [CrossRef]

33. Gibberd, J. Assessing sustainable buildings in developing countries-the sustainable building assessment tool (SBAT) and the sustainable building lifecycle (SBL). In Proceedings of the World Sustainable Building Conference, Tokyo, Japan, 27-29 September 2005.

34. Si, B.; Tian, Z.; Jin, X.; Zhou, X.; Tang, P.; Shi, X. Performance indices and evaluation of algorithms in building energy efficient design optimization. Energy 2016, 114, 100-112. [CrossRef]

35. Attia, S.; Hamdy, M.; O’Brien, W.; Carlucci, S. Assessing gaps and needs for integrating building performance optimization tools in net zero energy buildings design. Energy Build. 2013, 60, 110-124. [CrossRef]

36. Touloupaki, E.; Theodosiou, T. Performance Simulation Integrated in Parametric 3D Modeling as a Method for Early Stage Design Optimization-A Review. Energies 2017, 10, 637. [CrossRef]

37. Evins, R. A review of computational optimisation methods applied to sustainable building design. Renew. Sustain. Energy Rev. 2013, 22, 230-245. [CrossRef]

38. Lin, B.; Chen, H.; Yu, Q.; Zhou, X.; Lv, S.; He, Q.; Li, Z. MOOSAS-A systematic solution for multiple objective building performance optimization in the early design stage. Build. Environ. 2021, 200, 107929. [CrossRef]

39. Kämpf, J.H.; Robinson, D. Optimisation of building form for solar energy utilisation using constrained evolutionary algorithms. Energy Build. 2010, 42, 807-814. [CrossRef]

40. Delgarm, N.; Sajadi, B.; Delgarm, S. Multi-objective optimization of building energy performance and indoor thermal comfort: A new method using artificial bee colony (ABC). Energy Build. 2016, 131, 42-53. [CrossRef]

41. Zhang, A.; Bokel, R.; Dobbelsteen, A.V.D.; Sun, Y.; Huang, Q.; Zhang, Q. Optimization of thermal and daylight performance of school buildings based on a multi-objective genetic algorithm in the cold climate of China. Energy Build. 2017, 139, 371-384. [CrossRef]

42. Carlucci, S.; Cattarin, G.; Causone, F.; Pagliano, L. Multi-objective optimization of a nearly zero-energy building based on thermal and visual discomfort minimization using a non-dominated sorting genetic algorithm (NSGA-II). Energy Build. 2015, 104, 378-394. [CrossRef]

43. Talaei, M.; Mahdavinejad, M.; Azari, R.; Prieto, A.; Sangin, H. Multi-objective optimization of building-integrated microalgae photobioreactors for energy and daylighting performance. J. Build. Eng. 2021, 42, 102832. [CrossRef]

44. Lin, S.-H.E.; Gerber, D.J. Designing-in performance: A framework for evolutionary energy performance feedback in early stage design. Autom. Constr. 2014, 38, 59-73. [CrossRef]

45. Davidson, S. Grasshopper: Algorithmic Modelling for Rhino 2019. Available online: http:/ / www.grasshopper3d.com/ (accessed on 21 January 2021).

46. Ladybug Tools LLC. Ladybug Tools. Available online: https://www.ladybug.tools/ladybug.html (accessed on 12 August 2021).

47. Jakubiec, J.A.; Reinhart, C.F. DIVA 2.0: Integrating daylight and thermal simulations using Rhinoceros 3D, DAYSIM and EnergyPlus. In Proceedings of the Building Simulation, Sydney, Australia, 14-16 November 2011.

48. Advanced Knowledge Laboratory, Inc. CFD Simulation for Architectural Design. Available online: http://www.akl.co.jp/en/ (accessed on 1 April 2020).

49. Wallicei. An Evolutionary Multi-Objective Optimization and Analytic Engine for Grasshopper 3D. Available online: https://www. wallacei.com/ (accessed on 12 August 2021).

50. Deb, K.; Pratap, A.; Agarwal, S.; Meyarivan, T. A fast and elitist multiobjective genetic algorithm: NSGA-II. IEEE Trans. Evol. Comput. 2002, 6, 182-197. [CrossRef]

51. Si, B.; Wang, J.; Yao, X.; Shi, X.; Jin, X.; Zhou, X. Multi-objective optimization design of a complex building based on an artificial neural network and performance evaluation of algorithms. Adv. Eng. Inform. 2019, 40, 93-109. [CrossRef]

52. Yu, W.; Li, B.; Jia, H.; Zhang, M.; Wang, D. Application of multi-objective genetic algorithm to optimize energy efficiency and thermal comfort in building design. Energy Build. 2015, 88, 135-143. [CrossRef]

53. Mackey, C.; Galanos, T.; Norford, L.; Roudsari, M.S. Wind, sun, surface temperature, and heat island: Critical variables for high-resolution outdoor thermal comfort. In Proceedings of the 15th International Conference of Building Performance Simulation Association, San Francisco, CA, USA, 7-9 August 2017. 
54. CUHK. Urban Climatic Map and Standards for Wind Environment-Feasibility Study; Final Report; School of Architecture, The Chinese University of Hong Kong: Hong Kong, China, 2009.

55. Lin, T.-P.; Matzarakis, A. Tourism climate and thermal comfort in Sun Moon Lake, Taiwan. Int. J. Biometeorol. 2008, 52, 281-290. [CrossRef]

56. Mannor, S.; Jin, X.; Han, J.; Zhang, X. K-Means Clustering. In Encyclopedia of Machine Learning; Springer Science and Business Media: Berlin, Germany, 2011; pp. 563-564. 